\title{
Synthesis and characterization of Acacia lignin-gelatin film for its possible application in food packaging
}

\author{
Keshaw Ram Aadil, Anand Barapatre and Harit Jha*
}

\begin{abstract}
Background: The aim of the present investigation was to develop Acacia lignin-gelatin (LG) blended films using glycerol as plasticizer and to establish correlation between lignin contents and structure, thermal and mechanical properties of the film. Acacia lignin extracted by alkali method was used for the preparation of LG blended films by solution casting method.

Results: Solubility and swelling tests of the films concluded that the lignin incorporation reduced water affinity of film. Lignin incorporation produces a noticeable plasticizing effect on the blended film, showing optimum values for film incorporated with 20 and $30 \%$ (w/v) lignin, as deduced from their mechanical and thermal properties. Lignin blended film had lower glass transition temperatures $\left(T_{\mathrm{g}}\right)$ as compared to control gelatin. Infrared spectroscopy (FTIR) analysis of films suggested that lignin interacts with gelatin by hydrogen bonding and hydrophobic interaction consequently creating conformational changes. Atomic force microscopic (AFM) study displays smooth surface of synthesized films. Light barrier properties of film revealed that the lignin addition improved barrier properties against UV light in the range of $280-350 \mathrm{~nm}$. Furthermore, the lowest scavenging activity was observed in LG-E (111.10 $\mu \mathrm{g}$ / $\mathrm{ml})$ trailed by LG-D $(249.29 \mu \mathrm{g} / \mathrm{ml})$ and LG-C $(259.53 \mu \mathrm{g} / \mathrm{ml})$.
\end{abstract}

Conclusions: The LG films showed improved light barrier and antioxidant properties with low cytotoxicity, displaying great potential in food packaging and coating for preventing ultraviolet induced lipid oxidation with an extended biomedical applications.

Keywords: Acacia lignin, Gelatin, Edible film, Antioxidant activity, In vitro cytotoxicity

\section{Background}

In the recent past, much attention has been focused to replace petroleum based products, with biodegradable materials owing to their cost-effective nature and good mechanical properties. Biopolymers are considered as the feasible alternative materials for the replacement of petrochemical based products. Gelatin is a protein and an important biopolymer with a wide range of functional properties, such as biodegradability, biocompatibility, film forming, and gelling (Cao et al. 2007). It is derived from the chemical degradation of collagen, and mainly, consist of glycine, proline and 4-hydroxyproline

\footnotetext{
*Correspondence: harit74@yahoo.co.in

Department of Biotechnology, Guru Ghasidas Vishwavidyalaya (A Central University), Bilaspur, Chhattisgarh, India
}

(Pena et al. 2010). It has a triple-helix structure stabilized mainly by the formation of inter-chain hydrogen bonds between carbonyl and amines groups (Rivero et al. 2010). It is a promising raw material for biodegradable packaging materials due to its good barrier properties against oxygen and aromas with intermediate relative humidity (Carvalho et al. 2008; Jongjareonrak et al. 2006). But several of the potential applications of gelatin films require improvements in some of the properties like mechani$\mathrm{cal}$, water and light barrier properties. Normally, gelatin is brittle in dry state with high moisture absorption due to tightly bound hydrogen bonds, hydrophobic interaction and the polar groups of amino acids, present in the gelatin structure (Karnnet et al. 2005). To overcome this problem, the addition of plasticizers and natural fillers 
having antioxidant and antibacterial properties, such as polyphenols would be significant to improve their physico-chemical and functional properties (Pena et al. 2010; Nunez-Flores et al. 2013). The incorporation of fillers aids, to reduce the intrinsic brittleness of the films by decreasing intermolecular forces, increasing the mobility of polymeric chains and improving their flexibility, and thus, will extend the functional properties of the film and provide an active packaging biomaterial (Nunez-Flores et al. 2013).

Lignin, a natural biopolymer, mostly derived from wood, is an enormous and renewable reservoir of latent polymeric materials and aromatic chemicals. It is also a waste product of paper and pulp industries wherein approximately 50 million tons of lignin are generated annually (Sivasankarapillai and McDonald 2011; Zeng et al. 2014; Saini et al. 2015). The complex polyphenolic structure and numerous functional groups of lignin are useful in their effective utilization for the development of polymers, adhesives, coating, additives, carbon fibers, activated carbon, foams and metal nanoparticles (Park et al. 2008; Wang et al. 2009; Aadil et al. 2016). The effective use of lignin in blends with different biopolymers, such as starch (Bhat et al. 2013), gelatin (Nunez-Flores et al. 2013) and synthetic polymers like poly(vinyl alcohol), poly(ethylene), poly(lactic acid), poly(vinyl chloride) have also been reported in the literature (Gordobil et al. 2014; Sahoo, et al. 2011). Being a natural and potent antioxidant, Acacia wood lignin is better suited for the development of safe, biodegradable and functional edible film as compared to other biopolymers (Aadil et al. 2014; Barapatre et al. 2015). However, there are limited reports on the effect of Acacia lignin on the film forming ability, and physical and chemical properties of the gelatinlignin admixtures.

In the present investigation, attempts were made to prepare the film based on Acacia lignin and gelatin as a safe and biodegradable packaging material. Gelatin has been used in this study due to its biocompatibility, biodegradability, film forming ability and its efficacy as surface coating film to protect food from drying and exposure to light and oxygen. To explore the applicability of prepared lignin-gelatin films in packaging materials, physico-chemical properties, antioxidant activity and in vitro cytotoxicity of these films were evaluated.

\section{Methods}

\section{Materials}

The Acacia wood powder was obtained from the local timber mill of Bilaspur, Chhattisgarh, India. The dried wood powder of Acacia was first dewaxed using toluene-ethanol $(2: 1, \mathrm{v} / \mathrm{v})$ in a soxhlet extractor and dried in an oven at $60{ }^{\circ} \mathrm{C}$ before lignin extraction. 2, 2,-dipheny 1-1-picrylhydrazyl (DPPH) and sulforhodamine B (SRB) were purchased from Sigma-Aldrich (USA). Commercial type-A gelatin, trichloroacetic acid (TCA) and acetic acid were purchased from Merck, India. Glycerol and sodium hydroxide were obtained from Hi-Media Pvt. Ltd., Mumbai, India. Millipore deionized grade water was used for all the experiments. All other reagents used were of analytical grade.

\section{Isolation of lignin from Acacia wood powder}

Lignin was extracted from dewaxed Acacia wood by alkali extraction method as described previously by Aadil et al. (2014). In brief, alkali extraction dried wood was treated with $0.2 \mathrm{~N} \mathrm{NaOH}$ solution (solid/liquid ratio $1: 15(\mathrm{w} / \mathrm{v}))$ at $120{ }^{\circ} \mathrm{C}$ for $45 \mathrm{~min}$. The dark brown liquor was separated by filtration and concentrated in oven at $60{ }^{\circ} \mathrm{C}$ to reduce the volume. Dissolved hemicellulose fraction was removed through precipitation by reducing the $\mathrm{pH}$ of filtrate up to 5.5 with $5 \mathrm{~N} \mathrm{HCl}$ followed by adding three volumes of $95 \%$ ethanol. After removing hemicellulose fraction by filtration, soluble lignin fractions were obtained by re-precipitation of lignin at $\mathrm{pH} 1.5-2.0$. To the end, the extracted lignin was washed thoroughly with deionized water to remove the residual impurities. The extracted alkali lignin was labeled as A2.

\section{Preparation of lignin-gelatin film}

The films were prepared by a solution casting method. Gelatin powder $(4 \% \mathrm{w} / \mathrm{v})$ was first dissolved in Millipore deionized water at $60{ }^{\circ} \mathrm{C}$ for $30 \mathrm{~min}$. Further, Lignin (1\% $\mathrm{w} / \mathrm{v}$ in $0.1 \mathrm{~N} \mathrm{NaOH}$ ) was added in pre-solubilized gelatin in different ratios. To plasticize gelatin-lignin film, glycerol $(0.6 \%, \mathrm{w} / \mathrm{v})$ was added in lignin-gelatin mixture. Thus, the films were prepared in various ratios of gelatin: lignin (100:0, 90:10, 80:20, 70:30, and 60:40) and labeled as LG-A, LG-B, LG-C, LG-D and LG-E. After stirring at $60{ }^{\circ} \mathrm{C}$ for $1 \mathrm{~h}$, the filmogenic solution $(40 \mathrm{ml})$ was cast on petri plates $(13.5 \mathrm{~cm}$ diameter) precoated with aluminum foil and dried in an oven at $60^{\circ} \mathrm{C}$ for $2 \mathrm{~h}$. The film obtained was peeled off and kept in desiccator containing $\mathrm{P}_{2} \mathrm{O}_{5}$ maintained (at $25 \pm 2{ }^{\circ} \mathrm{C}$ ) at $0 \%$ relative humidity $(\mathrm{RH})$ until further characterization. Initial test was performed to define the most appropriate film thickness for the different reaction mixture containing varying concentration of the lignin and constant amount of glycerol as plasticizer.

\section{Measurement of film thickness}

The thickness of the films was measured using the manual digital micrometer (Mitutoyo Manufacturing, Japan) with an accuracy of $0.001 \mathrm{~mm}$. Ten different positions were measured and the average thickness was calculated for each film. 


\section{Moisture content}

Moisture content (MC) was measured by the method described by Cao et al. (2007). Moisture content was calculated by the equation:

$$
\mathrm{MC}(\%)=\left(M_{\mathrm{i}}-M_{\mathrm{f}}\right) / M_{\mathrm{i}} \times 100,
$$

where $M_{\mathrm{i}}$ was the initial weight of the film expressed as dry matter and $M_{\mathrm{f}}$ was the final weight of dried samples. All experiments were carried out in triplicate.

\section{Water solubility}

Water solubility (WS) of films was determined according to the method described by Nunez-Flores et al. (2013). WS was calculated by the equation:

$$
\mathrm{WS}(\%)=\left(W_{\mathrm{i}}-W_{\mathrm{f}}\right) / W_{\mathrm{i}} \times 100,
$$

where $W_{\mathrm{i}}$ was the initial weight of film expressed as dry matter and $W_{\mathrm{f}}$ was the weight of the undissolved desiccated film residue. All experiments were carried out in triplicate.

\section{Swelling properties}

Swelling properties of the films were tested by the method described by $\mathrm{Mu}$ et al. (2012). Films $(2 \times 2 \mathrm{~cm}$ in size) were immersed in $25 \mathrm{ml}$ of deionized water at room temperature $\left(25 \pm 2{ }^{\circ} \mathrm{C}\right)$. The weight gain of swollen films $\left(W_{\mathrm{s}}\right)$ was measured at selected times, after blotting the surface with Whatman No. 1 filter paper, until equilibrium was reached. The swelling ratio (SR) was calculated using the following equation:

$$
\mathrm{SR}(\%)=\left(W_{\mathrm{s}}-W_{\mathrm{d}}\right) /\left(W_{\mathrm{d}} \times 100\right)
$$

where $W_{\mathrm{s}}$ is the weight of swollen samples $(\mathrm{g}) ; W_{\mathrm{d}}$ is the weight of dry samples (g). The measurements were repeated three times for each type of film and an average was taken as the result.

\section{Light barrier properties}

The light transparency of films was measured at ultraviolet-visible range $(200-800 \mathrm{~nm})$ using a UV-Vis spectrophotometer (Shimadzu UV-1800, Japan). The film specimens were cut into a rectangle piece and placed in a spectrophotometer test cell directly and air was used as the reference. The opacity of film was calculated by the following equation:

$$
\text { Opacity }=A_{600} / X
$$

where $A_{600}$ was the absorption at $600 \mathrm{~nm}$, and $X$ is the film thickness (mm) (Al-Hassan and Norziah 2012). According to this equation, a higher value of transparency would indicate a lower degree of transparency. The measurement was repeated three times for each type of film, and an average was taken as the result.

\section{Mechanical properties}

Tensile strength (TS) and bursting strength (BS) of the films were determined according to ASTM standard method D882-01 (ASTM 2001) using a tensile strength and bursting strength tester (JSR Instruments, Roorkee, India).

\section{FTIR spectroscopy}

FTIR analysis was carried using a Perkin-Elmer Spectrum One FTIR spectrophotometer at the resolution of $4 \mathrm{~cm}^{-1}$ in the wave number region $400-4000 \mathrm{~cm}^{-1}$. Spectra of samples were obtained from discs containing $1.0 \mathrm{mg}$ sample in approximately $100 \mathrm{mg}$ potassium bromide $(\mathrm{KBr})$.

\section{Differential scanning calorimetry (DSC) analysis}

Calorimetric analysis was performed using a differential scanning calorimeter (Mettler Toledo DSC 822e), previously calibrated by running high purity indium. Samples of approximately $7 \mathrm{mg}( \pm 0.02 \mathrm{mg})$ were tightly encapsulated in aluminum pans and scanned under dry nitrogen (50 $\mathrm{ml} / \mathrm{min})$. An empty hermetic aluminum pan was used as reference. Freshly conditioned films were cooled to -50 or $0{ }^{\circ} \mathrm{C}$, at $10^{\circ} \mathrm{C} \mathrm{min}-1$ and scanned up to $300{ }^{\circ} \mathrm{C}$ at a heating rate of $10{ }^{\circ} \mathrm{C} / \mathrm{min}$. After cooling at the same rate down to the corresponding initial temperature, a second heating scan was run. Glass transition temperatures, $T_{\mathrm{g}}$ $\left({ }^{\circ} \mathrm{C}\right)$, were calculated by the inflection-midpoint method and usually reported on the first heating scans to thermally characterize the same material used in the rest of the analyses. The energetic parameter was normalized to a dry matter content of the corresponding film sample.

\section{Thermo-gravimetric analysis}

Thermo-gravimetric analysis (TGA) and a derivative of TGA (DTG) of synthesized films was performed using a thermo-gravimetric analyzer (Diamond STA-6000, Perkin-Elmer, Shelton, USA) under a nitrogen atmosphere at a flow rate of $200 \mathrm{ml} / \mathrm{min}$. Film samples (about $5 \mathrm{mg}$ ) were heated from room temperature to $700{ }^{\circ} \mathrm{C}$ at a heating rate of $10^{\circ} \mathrm{C} / \mathrm{min}$ to obtain individual spectra.

\section{Scanning electron microscopy (SEM)}

SEM analysis (ZEISS EVO Series SEM Model EVO 18) was performed for microstructural analysis of the film. Film samples were mounted on a metal stub and gold coated using sputter coating technique for $20 \mathrm{~s}$ to make them conducting. Images of the film were taken at $20 \mathrm{kV}$ accelerating voltage at different magnifications.

\section{Atomic force microscopy (AFM)}

AFM imaging was accomplished for topographic and surface study of the film using an AFM, (SPM 1600, 
Shimadzu, Japan) operating in the dynamic mode with a silicon cantilever tip. A thin film of the sample was prepared on a glass slide by dropping $100 \mu \mathrm{l}$ of the sample solution. The sample coated slide was kept on vacuum desiccator prior to analysis. The topographic images were obtained by scanning the area from $10 \times 10 \mu \mathrm{m}$ to $625 \times 625 \mathrm{~nm}$. The SPM online software was used to process the collected images.

\section{DPPH radical scavenging activity assay}

The DPPH free radical scavenging assay was performed by the method described previously by Aadil et al. (2014). The stock solution was prepared by dissolving $24 \mathrm{mg}$ DPPH in $100 \mathrm{ml}$ methanol and the working solution was obtained by mixing $10 \mathrm{ml}$ stock solution with $45 \mathrm{ml}$ methanol so as to obtain an absorbance of $1.1 \pm 0.05$ at $517 \mathrm{~nm}$. Samples were dissolved in deionized water, followed by centrifugation. $2850 \mu \mathrm{l}$ aliquot of DPPH solution was mixed with $150 \mu \mathrm{l}$ of films extract. The reaction mixture was incubated in the dark for $30 \mathrm{~min}$ at room temperature followed by measurement of absorbance at $517 \mathrm{~nm}$. The scavenging activity was calculated as follows:

$$
\text { Scavenging activity }(\%)=\left[\left(A_{0}-A_{i}\right) / A_{0}\right] \times 100,
$$

where $A_{0}$ was the absorbance of the control, and $A_{\mathrm{i}}$ was the absorbance of the sample. The radical scavenging activity was expressed as $\mathrm{IC}_{50}$ value, the concentration required to quench $50 \%$ of initial DPPH radical. The commercial lignosulphonate was used as standard.

\section{In vitro cytotoxicity}

The cell growth inhibitory capacity of alkali lignin (A2) (used for film preparation) and lignin-gelatin blended film (LG-D) were tested at four different concentration $(10,20,40,80 \mu \mathrm{g} / \mathrm{ml})$ on the human hepatoma HEP-G2 cell line using sulforhodamine B (SRB) assay as described by Skehan et al. (1990). The cell viability percentage was calculated using following formula:
The concentration required to inhibit $50 \%$ cell growth was considered as $\mathrm{IC}_{50}$ value of the samples.

\section{Statistical analysis}

All assays were performed in triplicates and the results were validated statistically using one-way analysis of variance (ANOVA). All the tests were considered statistically significant at $p<0.05$ and the means were compared using Turkey's multiple comparison test. The analysis was carried out using Graph Pad Prism Software Version 5. Results were presented as mean value \pm standard deviation (SD).

\section{Results and discussion}

The films obtained from different ratios of lignin-gelatin preparations were homogeneous, flexible, easily handled, non-sticky and partially soluble in water after $24 \mathrm{~h}$ at $25{ }^{\circ} \mathrm{C}$. The thickness of lignin-gelatin films ranged between 0.12 and $0.17 \mathrm{~mm}$ among the films (Table 1). The control gelatin film appeared transparent yellow. However, the visible appearance of LG film was light brown due to the chromophoric effect of lignin (Fig. 1), which is consistent with the reports of Vanin et al. (2005) and Carvalho et al. (2008).

\section{Moisture content and water solubility}

Moisture content of Acacia lignin blended gelatin film is summarized in Table 1. The moisture content ranged between $8.96 \%$ (LG-A) to $16.43 \%$ (LG-D) and $16.2 \%$ (LG-E) among the film. The high moisture content was found in LG-D and LG-E. In this regard, it could be explained that water is not only linked with the film matrix, but is also retained due to the hydrophilic nature of glycerol.

Solubility of edible film in water is an essential asset and water resistance is typically mandatory for possible commercial applications of the edible film. After the $24 \mathrm{~h}$ incubation in distilled water, the control gelatin film

$$
\text { Cell viability }(\%)=\frac{(\text { Absorbance of control group }- \text { Absorbance of sample treated group })}{\text { Absorbance of control group }} \times 100
$$

\begin{tabular}{|c|c|c|c|c|c|c|}
\hline Samples & Thickness (mm) & $\begin{array}{l}\text { Moisture content } \\
(\%)\end{array}$ & Water solubility (\%) & $\begin{array}{l}\text { Swelling property } \\
(\%)\end{array}$ & $\begin{array}{l}\text { Bursting index }(\mathrm{kg} / \\
\left.\mathrm{cm}^{2}\right)\end{array}$ & $\begin{array}{l}\text { Tensile strength } \\
\text { (MPa) }\end{array}$ \\
\hline LG-A & $0.17 \pm 0.02^{\mathrm{a}}$ & $8.96 \pm 0.68^{a}$ & $59.15 \pm 0.54^{d}$ & $511.48 \pm 1.10^{a}$ & $9.34 \pm 2.02^{b}$ & $1.22 \pm 0.31^{\mathrm{d}}$ \\
\hline$L G-B$ & $0.16 \pm 0.01^{\mathrm{a}}$ & $10.03 \pm 0.61^{\mathrm{a}}$ & $49.34 \pm 0.64^{c}$ & $438.75 \pm 1.02^{b}$ & $5.32 \pm 0.93^{a}$ & $0.74 \pm 0.17^{b c}$ \\
\hline$L G-C$ & $0.12 \pm 0.01^{\mathrm{a}}$ & $14.3 \pm 0.36^{b}$ & $43.98 \pm 0.33^{b}$ & $432.86 \pm 0.93^{c}$ & $7.57 \pm 0.97^{a b}$ & $0.87 \pm 0.11^{b d}$ \\
\hline LG-D & $0.12 \pm 0.005^{b}$ & $16.43 \pm 0.45^{c}$ & $33.37 \pm 0.90^{\mathrm{a}}$ & $425.80 \pm 0.59^{d}$ & $4.96 \pm 0.67^{\mathrm{a}}$ & $0.46 \pm .007^{\mathrm{a}}$ \\
\hline LG-E & $0.13 \pm 0.002^{a}$ & $16.2 \pm 0.20^{c}$ & $32.57 \pm 0.58^{a}$ & $417.13 \pm 0.70^{e}$ & $5.91 \pm 2.61^{a}$ & $0.28 \pm 0.06^{\mathrm{a}}$ \\
\hline
\end{tabular}

Table 1 Physical properties of lignin-gelatin blended film

Values represent mean \pm standard deviation (SD) of three independent experiments $(n=3)$. Different letters in the same column indicate a statistically significant difference $(p \leq 0.05)$ 


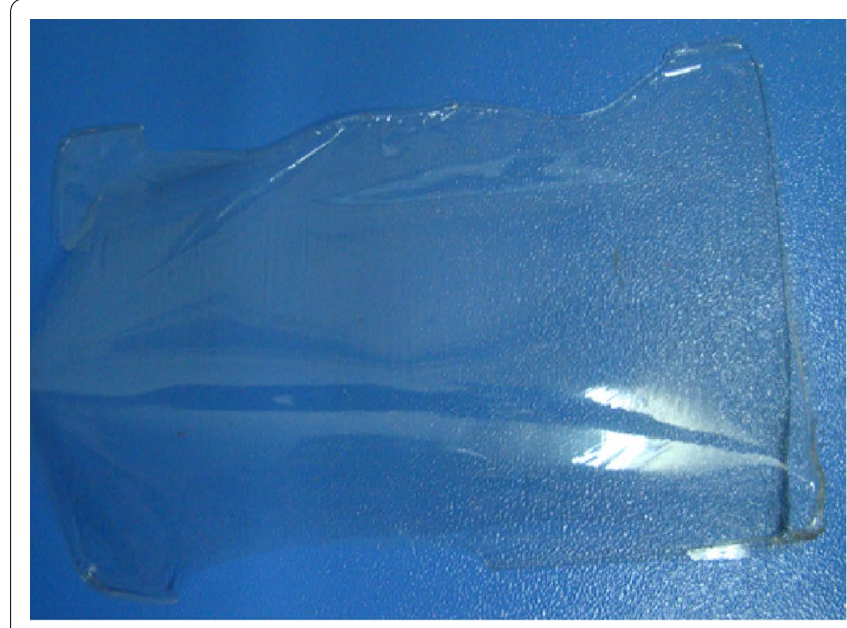

Control film (LG-A)

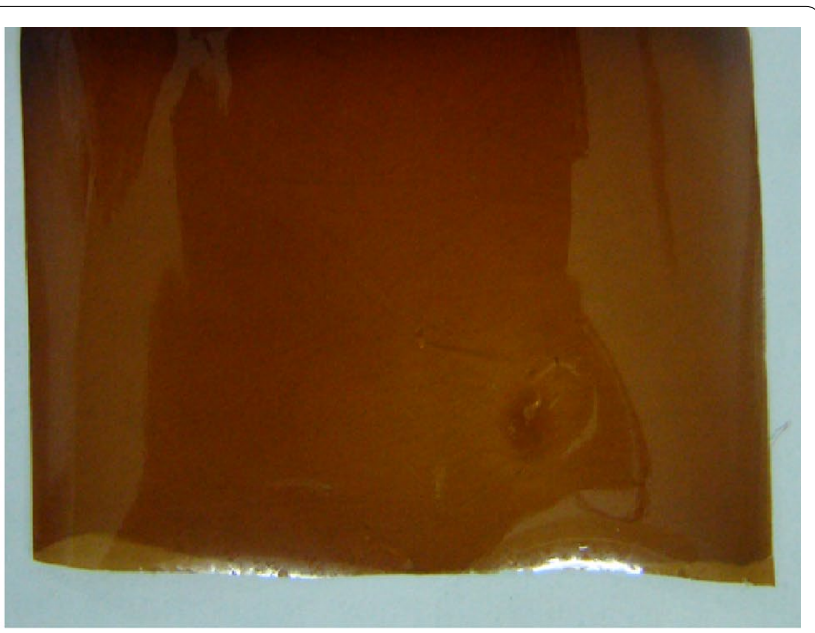

Lignin-gelatin cross-linked film (LG-D)

Fig. 1 Photographs of prepared gelatin (LG-A) and lignin-gelatin cross-linked film (LG-D)

consequently altered its shape, while the Acacia ligningelatin films were found to retain their integrity. Addition of lignin into gelatin film brought about a pronounced decrease in film solubility, from 59.15 (control) to $32.57 \%$ (LG-E) (Table 1). The high water resistance property of lignin-gelatin blended film is possibly due to the interaction and miscibility of phenolic compounds of lignin with amino groups of gelatin. Similar behavior was observed for sago starch films incorporated with lignin isolated from oil palm black liquor waste (Bhat et al. 2013). Literature also suggests that the incorporation of lignin alters the helical structure of gelatin, thereby, subsequently reducing the water solubility of the film (Nunez-Flores et al. 2012; Pena et al. 2010).

\section{Swelling properties}

The swelling ratios of lignin-gelatin blended films reduced with increase in concentration of lignin. Swelling ratio was found significantly higher in control (LG-A: $511.48 \%$ ) film, while the swelling percentage of LG-B, LG-C, LG-D and LG-E (417.13\%) film was recorded lower than control (Table 1). The decrease of swelling values might be due to the interaction between lignin and gelatin molecules by hydrophobic or hydrogen bonding, which reduced water uptake by gelatin meanwhile polarside-chain groups become less exposed to water molecules (Bigi et al. 2002). Cao et al. (2007) reported that the degree of swelling, significantly decreased to 30.91 and $42.15 \%$ as the concentration of ferulic acid and tannic acid increased. The total phenolic contents of Acacia lignin used in the study was found to be $73.01 \pm 3.2 \mu \mathrm{g}$ in terms of gallic acid equivalent per mg of extracted lignin fraction as reported in our previous study (Aadil et al. 2014).

\section{Light barrier properties}

The UV absorbance at $280 \mathrm{~nm}$ was high for LG films as compared to control (LG-A), with high transparency value, and thus, LG films provide excellent barrier properties against UV light in the range of $280-350 \mathrm{~nm}$, which induces lipid oxidation in the storage food $(\mathrm{Mu}$ et al. 2012). It was also observed that the light transparency of the LG films increased with increasing concentration of lignin. The opacity at $600 \mathrm{~nm}$ of LG films significantly increased from 3.51 (LG-B) to 5.26 (LG-E) as compared to control films (0.8) (Fig. 2). The higher UV light absorption capacity of LG film, is due to the chromophoric nature of lignin, which is capable of defending against UV light radiation (Ban et al. 2007). Similar results were reported for tuna-fish gelatin films with the addition of murta extract (Gómez-Guillén et al. 2007).

\section{Mechanical properties}

The result showed that as the lignin content in the film increased, tensile (TS) and bursting strength (BS) decreased. TS of the film ranged between 0.28 anbd 1.2 $\mathrm{MPa}$, and the highest value was exhibited for LG-A, while the addition of lignin significantly decreased the TS of the film (Table 1). The highest bursting strength was observed in LG-A, whereas the lowest was observed in LG-D. Acacia lignin incorporation created an apparent plasticizing effect in gelatin film, as assumed from significant decrease in both tensile and bursting strength. It has been reported that lignin provides miscibility with 


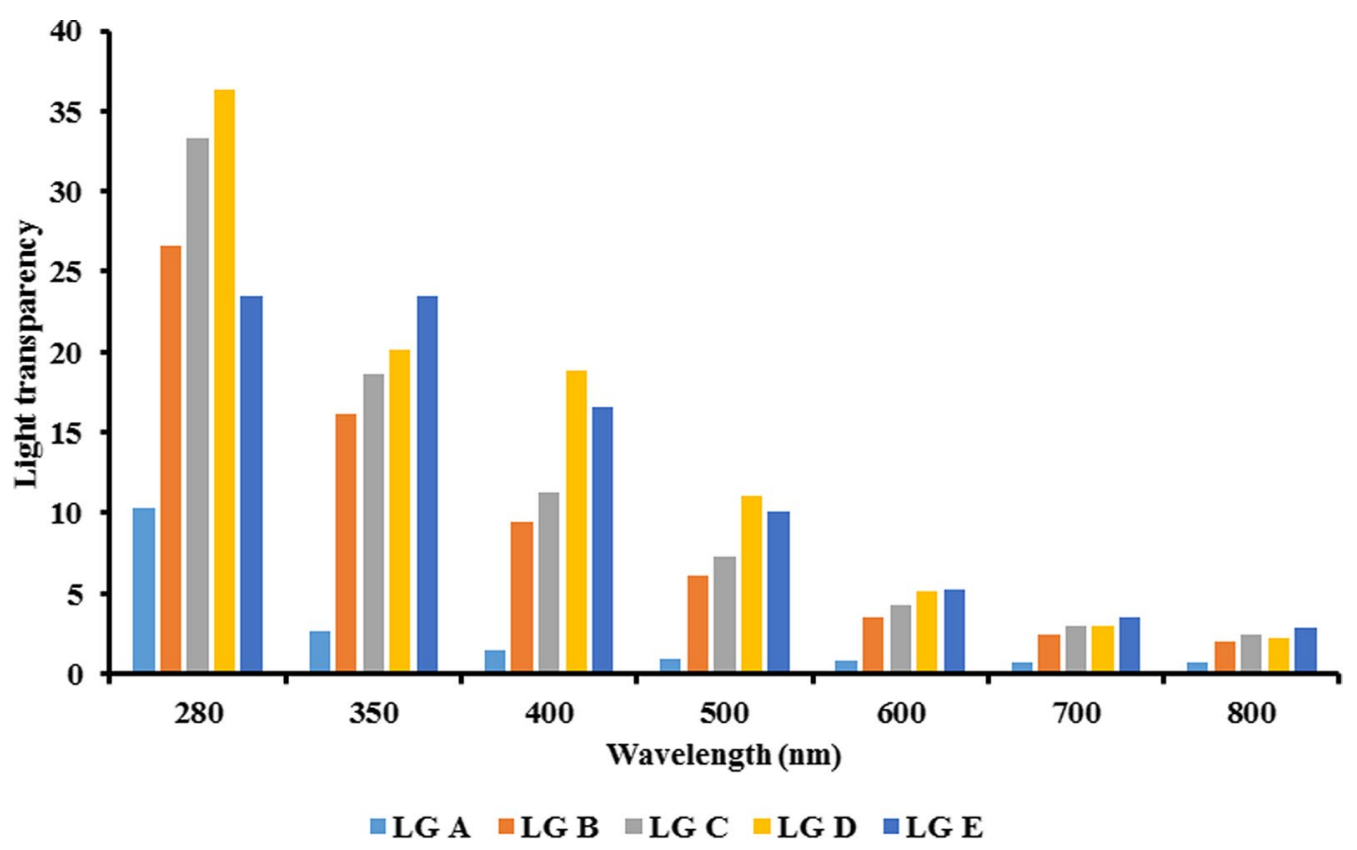

Fig. 2 Light transparency of different lignin-gelatin blended films

other polymers and act as a plasticizing agent in blend films, but only when added in moderate concentrations (Nunez-Flores et al. 2013). The decrease in TS and BS in the lignin-gelatin blended film can be associated with high moisture content of LG-D and LG-E and deceptive plasticizing effect of lignin leading to a decrease in intermolecular attraction forces between polymer chains (Cuq et al. 1997).

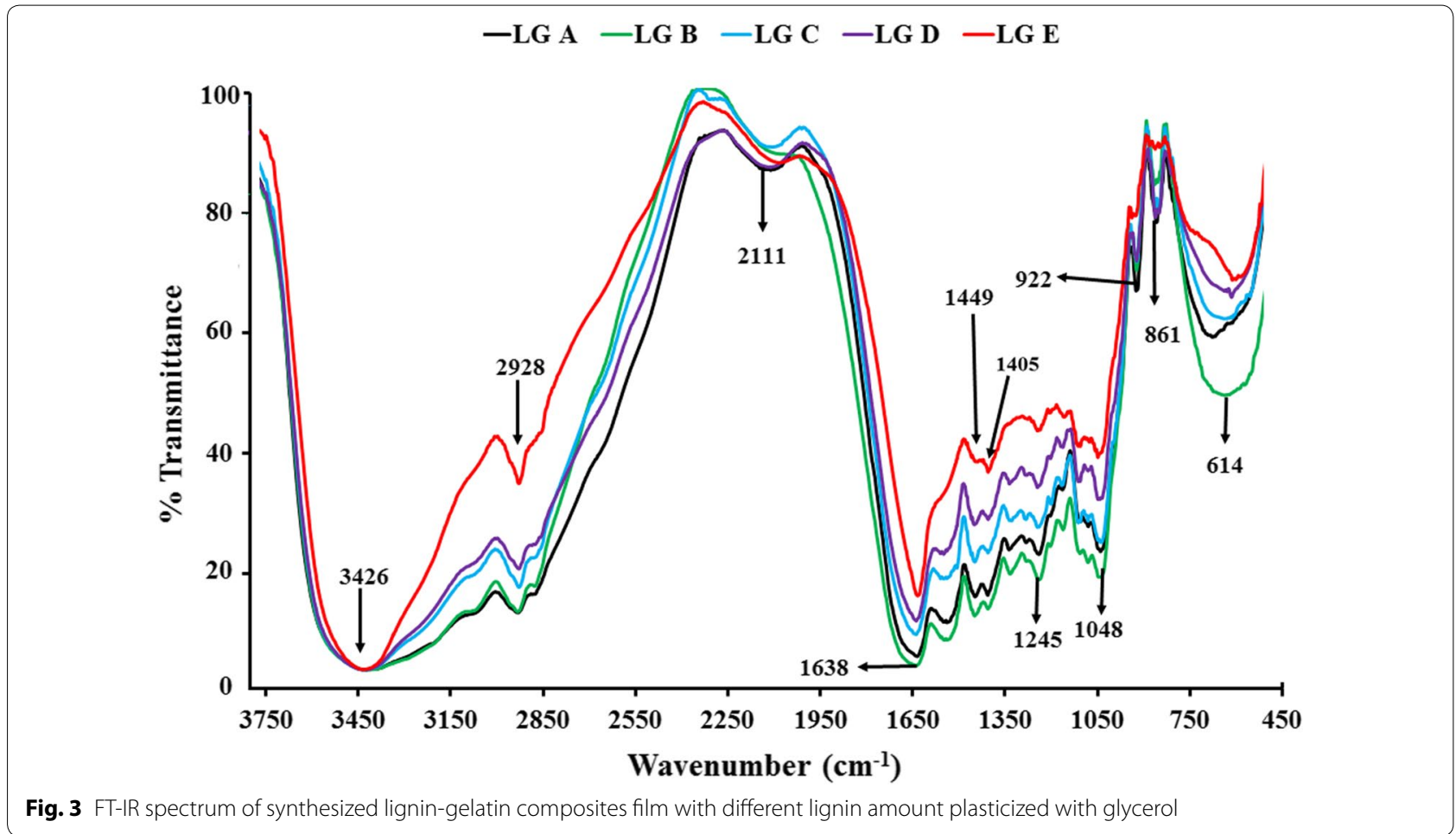




\section{FTIR spectra}

Lignin incorporation triggered a noticeable reduction in the intensity of amide $\mathrm{A}\left(3280 \mathrm{~cm}^{-1}\right)$, amide I $\left(1634 \mathrm{~cm}^{-1}\right)$, amide II $\left(1538 \mathrm{~cm}^{-1}\right)$, and amide III $\left(1240 \mathrm{~cm}^{-1}\right)$ bands of gelatin film (Fig. 3). It was reported that partial replacement of gelatin by lignin is due to protein "dilution effect", such a decrease would be largely attributed to prominent lignin induced protein conformational changes, and particularly due to difference in amide I band (Nunez-Flores et al. 2013). The slight frequency up-shift of amide I peaks in the composite films (LG-A: 1634; LG-B: $1638 \mathrm{~cm}^{-1}$; LG-C and LG-D: $1638 \mathrm{~cm}^{-1}$; LG-E: $1634 \mathrm{~cm}^{-1}$ ) is possibly due to disruption of hydrogen bonding at the $\mathrm{C}=\mathrm{O}$ groups of gelatin polypeptides through the lignin intrusion.

The broad bands at $3421 \mathrm{~cm}^{-1}$ were characteristic of hydroxyl groups in phenolic and aliphatic structures. The band recorded at $2930 \mathrm{~cm}^{-1}$ indicates the $\mathrm{C}-\mathrm{H}$ group, this band intensity slightly decreased on addition of lignin. The band at $1040 \mathrm{~cm}^{-1}$ (LG-A) could be attributed to the interactions arising between plasticizers (C-O stretch of glycerol) (Bergo and Sobral 2007; Hoque et al. 2011). This band shifted marginally towards higher wavenumber at $1048 \mathrm{~cm}^{-1}$ in the LG-D and LG-E. The most pronounced changes in the films was in the range of $1634-865 \mathrm{~cm}^{-1}$ indicating strong intrusion caused by the lignin in the hydrogen bonding between water and imide residues (Nunez-Flores et al. 2013). This result is also consistent with the report of Cao et al. (2007). Initially, hydrophobic groups of polyphenol interact with the hydrophobic region of protein via hydrophobic interaction followed by the hydrogen bonding between phenolic hydroxyl groups of polyphenols and polar group of protein. Based upon the above mechanism and FTIR data, it might be hypothesized that the hydroxyl and carboxyl group of lignin interact with amino acids of gelatin via hydrogen bonding and hydrophobic interaction. The consequent cross-linked network improved the physical and mechanical properties of the LG films.

\section{Differential scanning calorimetry}

The thermogram of LG-A films showed glass transition $\left(T_{\mathrm{g}}\right)$ at $112.12{ }^{\circ} \mathrm{C}$ temperature, followed by an endothermic event with a normalized enthalpy value of $-1.00 \mathrm{~J} \mathrm{~g}^{-1}$ (Fig. 4). This transition is associated with the molecular segmental motion of amorphous structure. The $T_{\mathrm{g}}$ and endothermic peak of LG-A is most possibly due to the helix-coil transition, devitrification of $\alpha$-amino acid and imino acids like proline and hydroxyproline ( $\mathrm{Ma}$ et al. 2012; Hosseini et al. 2015). By incorporation of $20 \%$ $(\mathrm{w} / \mathrm{v})$ lignin (LG-C) and $40 \%$ (w/v) (LG-E), glass transition peak shifted slightly towards higher temperature (Fig. 3). In LG-C, two different $T_{\mathrm{g}}$ appeared at 116.59
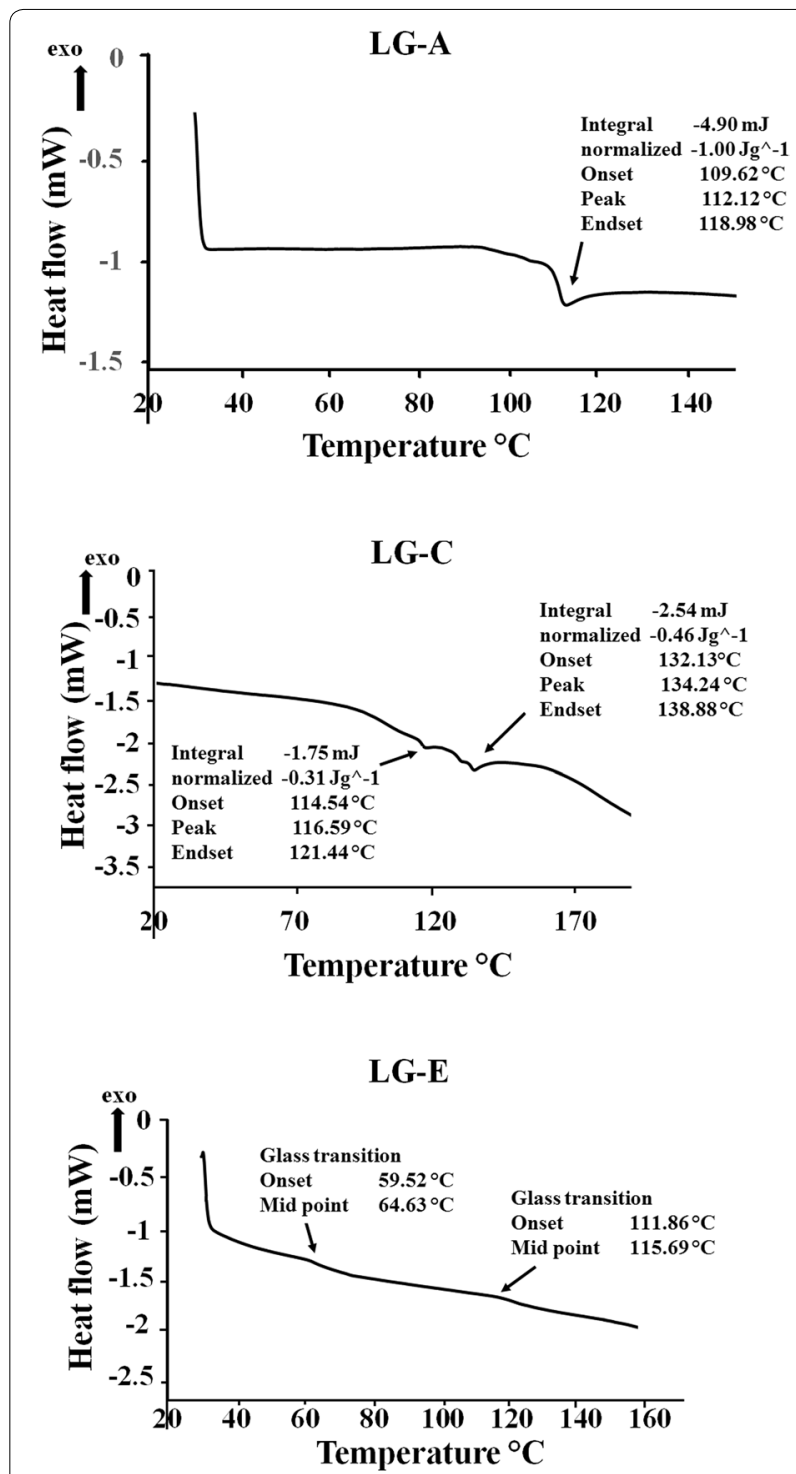

Fig. 4 Normalized typical DSC profiles (heat flow, $\mathrm{mW}$ vs temperature, ${ }^{\circ} \mathrm{C}$ ) of gelatin (LG-A) and lignin-gelatin films (LG-C and LG-E)

and $134.24{ }^{\circ} \mathrm{C}\left(\Delta \mathrm{H}=118.39\right.$ and $\left.31.03 \mathrm{~J} \mathrm{~g}^{-1}\right)$. Likewise, LG-E also showed two glass transition temperatures at 64.63 and $115.69^{\circ} \mathrm{C}$. $T_{\mathrm{g}}$ of LG films shifted towards lower temperature with the addition of lignin suggesting the phase separation and unfolding of helix-coil of gelatin molecules. The presence of two $T_{\mathrm{g}}$ temperature might be due to the presence of microphase separation or immiscibility between lignin and gelatin, which provide free volume for the gelatin molecules mobility (Huang et al. 2003; Nunez-Flores et al. 2013). The lower $T_{\mathrm{g}}$ value in LG-C and LG-E, suggests the plasticization ability of the lignin with gelatin at the proportions used in the composite films. The changes in the glass transition temperature suggest that the lignin interact with gelatin possibly 
through hydrogen bonding and hydrophobic interaction, subsequently, reducing the crystallinity and changing the helical structure of gelatin. Lignin addition might disturb the gelatin network by interacting with gelatin molecules, which prevents the gelatin coiling and create the intra molecular space (Pena et al. 2010). FTIR analysis also suggested that phenolic hydroxyl and carboxyl groups of lignin interact with amino acids of gelatin via hydrogen bonding and hydrophobic interaction. These results show similarity with previous reports on gelatin-tannin film, which suggested that new hydrogen bonding between hydroxyl groups of tannin and a polar group of gelatin is formed (Pena et al. 2010).

\section{Thermo-gravimetric analysis (TGA)}

TGA analysis revealed that the maximum weight loss percentage was in a narrow range $\left(250-350{ }^{\circ} \mathrm{C}\right)$ for all the films (LG-A, LG-C and LG-E) (Fig. 5a). Among all the films, initial degradation stage was between 50 up to $110{ }^{\circ} \mathrm{C}$ due to the presence of moisture. The small shoulders around $245-250{ }^{\circ} \mathrm{C}$ were observed at the second stage and attributed to the protein chain breakage and
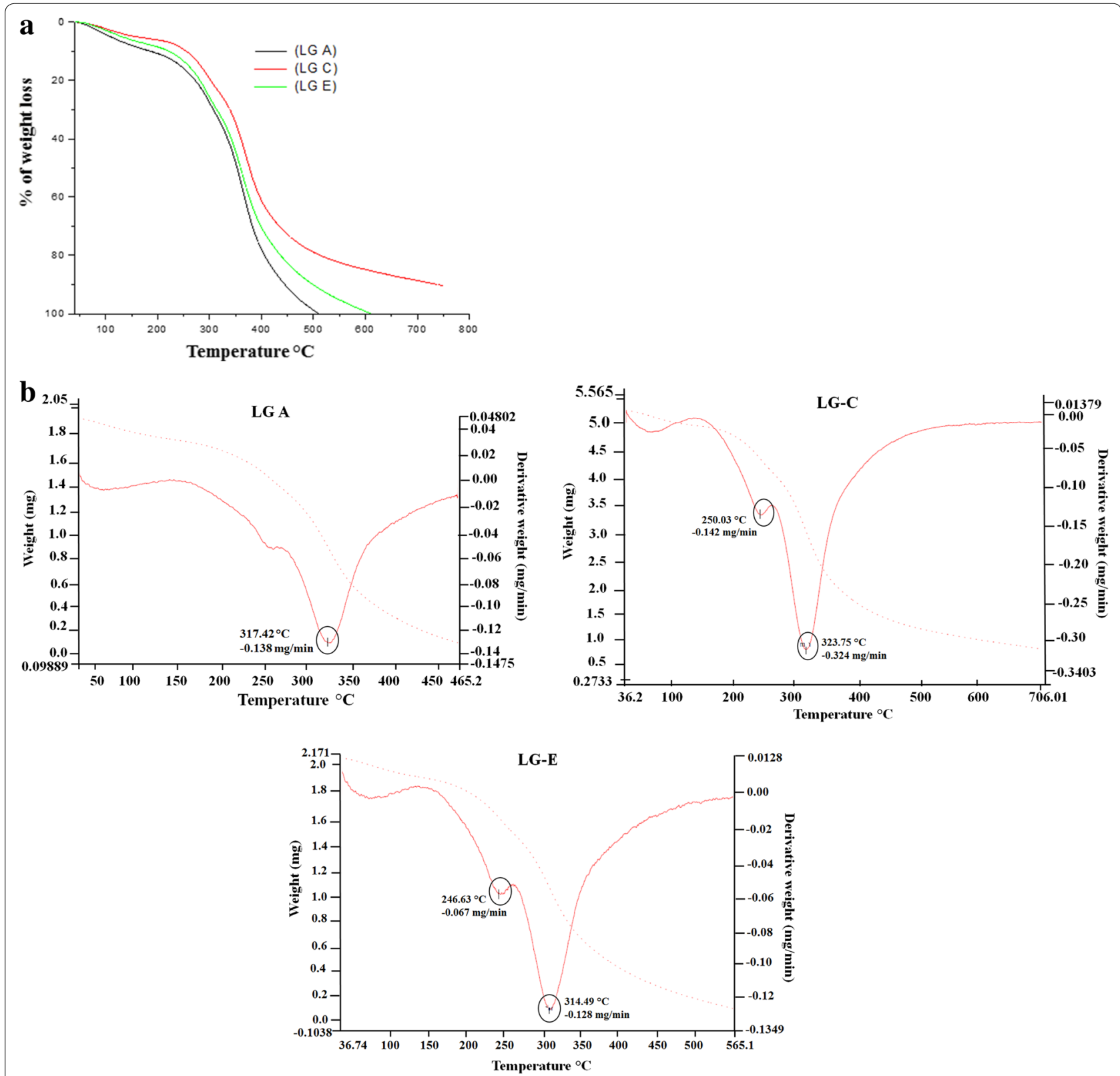

Fig. 5 TGA thermograms of lignin-gelatin blended films (LG-A, LG-C and LG-E). a Weight loss percentage, b differential weight loss rate (DTG) 
peptide bond disruption of gelatin (Mu et al. 2012; Pena et al. 2010). The third steps of major thermal degradation were observed around $323^{\circ} \mathrm{C}$ in LG-C and $314^{\circ} \mathrm{C}$ in LG-E which might be due to the thermal decomposition of gelatin and lignin (Fig. 5b). Lignin degradation, the third step, occurred gradually from $250-350{ }^{\circ} \mathrm{C}$, probably due to the breakdown of lignin $\mathrm{C}-\mathrm{C}$ linkages (Dominguez et al. 2008). The higher temperature step $\left(T>550{ }^{\circ} \mathrm{C}\right)$ indicates the decomposition of thermally stable structure formed by reactions during heating. LG-C showed marginally enhanced thermal stability in contrast to the control (LG-A), suggesting good interaction between lignin and gelatin molecules at $20 \%$ lignin. The slight improvement of thermal stability of the lignin-gelatin film allows its possible applications in packaging, coating, lamination and other industries.

\section{SEM analysis}

The SEM analysis is very important to understand the miscibility and compatibility of the blend and their effect on the properties of materials. The micrograph of the lignin blended gelatin film is displayed in Fig. 6. No phase separation and clump formation was noted in the micrograph suggesting the homogenous, miscibility and good blending of lignin with gelatin.

\section{AFM analysis}

AFM is an excellent and advanced tool for topography analysis of materials (Milczarek et al. 2013). AFM surface topography mapping of $10 \times 10 \mu \mathrm{m}$ to $625 \times 625 \mathrm{~nm}$ areas on the surface of the lignin-gelatin film show that the film surface is smooth without clumping or aggregates of lignin and gelatin molecules; however, at the lower scanning areas of $1.25 \times 1.25 \mu \mathrm{m}$ some roughness was observed (Fig. 7). The height of the aggregates varied from the 20 to $99 \mathrm{~nm}$ at the scan area of $625 \times 625 \mathrm{~nm}$, the root mean square (RMS) roughness was approximately $20 \mathrm{~nm}$. AFM analysis suggests that lignin is completely miscible with gelatin and form a smooth film.

\section{DPPH radical scavenging activity}

It was found that the water soluble fraction of film from LG-E had the significantly strong scavenging activity against DPPH radicals. The highest scavenging activity was observed in LG-E (67.51\%), whereas the lowest values were observed for LG-A (14.12\%). The lowest $\mathrm{IC}_{50}$ values was observed for LG-E $(111.10 \mu \mathrm{g} / \mathrm{ml})$ followed by LG-D $(249.29 \mu \mathrm{g} / \mathrm{ml})$ and LG-C $(259.53 \mu \mathrm{g} / \mathrm{ml})$ (Fig. 8a). The results revealed that with the increase in lignin content, free radical scavenging capacity of LG film also increased. The $\mathrm{IC}_{50}$ value obtained from the DPPH radical scavenging activity of LG-E film was about threefold higher than the activity of different lignosulphonate (Nunez-Flores et al. 2012, 2013). These properties could be favorable for the protection of certain type of food preparation in which oxidation process may signify a limiting factor determining its self-life.

\section{In vitro cytotoxicity}

To use lignin as active food packaging material, it is of importance to study its possible cytotoxic effects. The $\mathrm{IC}_{50}$ value obtained for A2 $(149.67 \mu \mathrm{g} / \mathrm{ml})$ and LG-D $(229.34 \mu \mathrm{g} / \mathrm{ml})$ reveals that it has cytotoxic effects, but only at moderate concentrations (Fig. 8b). Earlier report on lignin cytotoxicity suggested that carbohydrates content and polydispersity affect for cytotoxicity of lignin (Ugartondo et al. 2008). Lignins with low carbohydrate contents and high polydispersity are the most cytotoxic. In our study, the cytotoxic effect of A2 and LG-D exhibited $\mathrm{IC}_{50}$ values lower to those reported for lignin powder
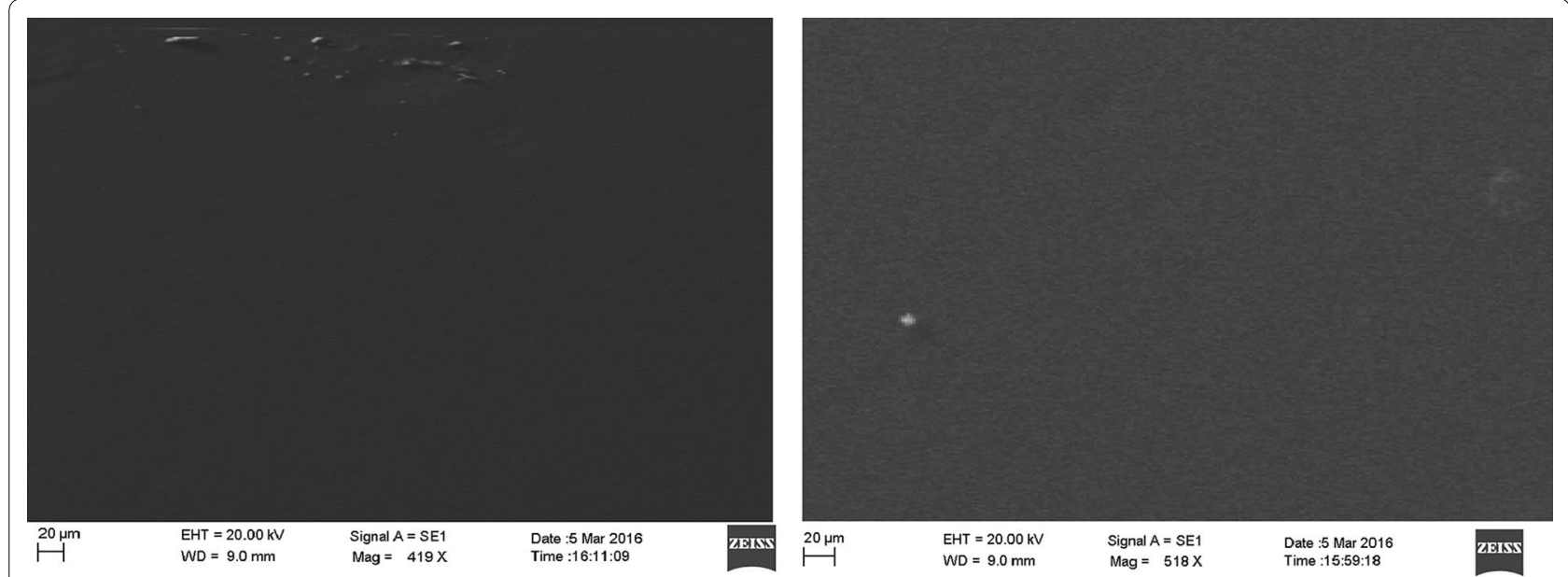

Fig. 6 SEM micrograph of lignin-gelatin film 

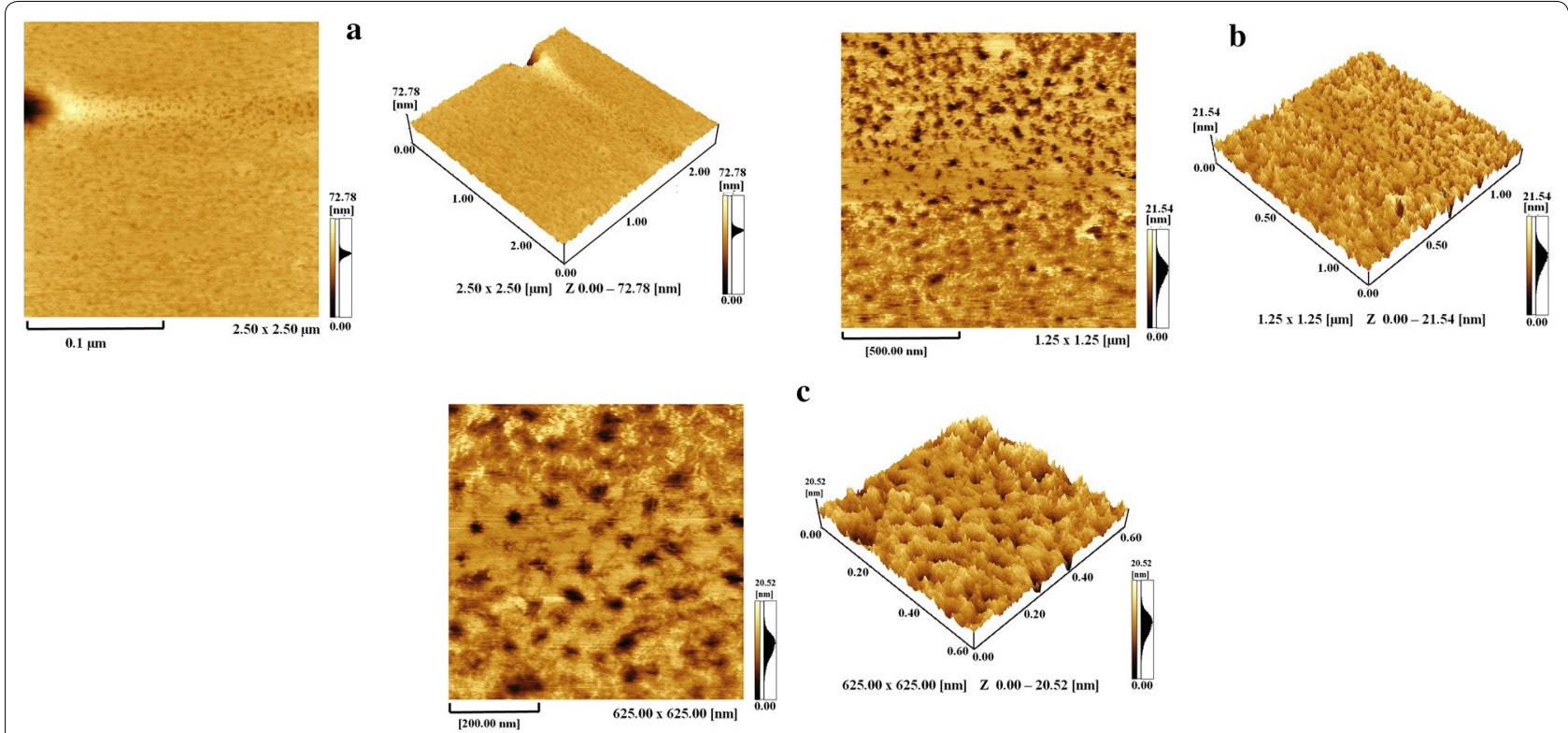

c

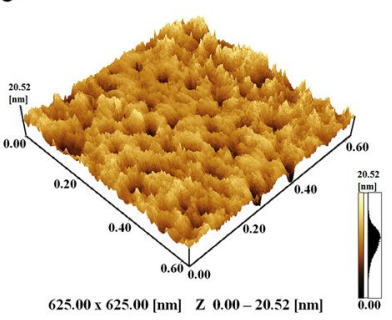

Fig. 7 AFM topography images of LG film: a topographic image of the $2.50 \times 2.50 \mu \mathrm{m}$ and 3D visualization, b $1.25 \times 1.25 \mu \mathrm{m}$ and $3 \mathrm{D}$ visualization, c $625 \times 625 \mathrm{~nm}$ and 3 D visualization
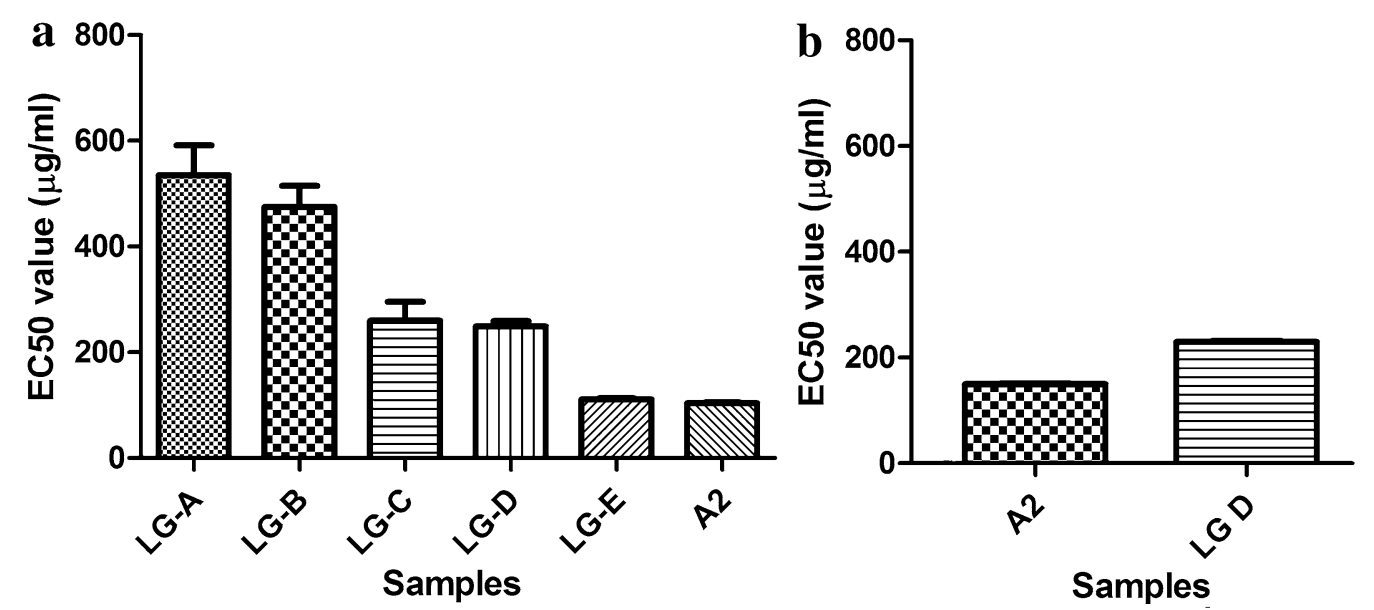

Fig. 8 a DPPH radical scavenging activity of LG films, b in vitro cytotoxic effect of alkali lignin (A2) and LG-D film against human hepatoma HEP-G2 cell line

$(631 \mu \mathrm{g} / \mathrm{ml})$. Lignin derivatives have been shown to be effective antioxidants at concentration that are not toxic to normal cells, hence extending their possible application in the preparation of active food packaging material (Nunez-Flores et al. 2013; Ugartondo et al. 2008).

\section{Conclusions}

The Acacia lignin is a useful component in preparation of gelatin based films. The blended film is flexible, stable and eco-friendly. Addition of lignin significantly affected the water solubility, swelling properties and tensile strength of the film. Structural analysis suggested that the lignin interacts with gelatin by hydrogen and hydrophobic interaction. Lignin blended film might show potential application in food packaging industries due to good UV light absorption capacity and antioxidant activity. In addition, lignin blended gelatin film could also be useful for biomedical and domestic applications, such as coating, lamination, and packaging of non-food material. 


\section{Authors' contributions}

KRA was involved in the synthesis and characterization of lignin-gelatin film and the preparation of the manuscript. AB helped in the performing the antioxidant assay. HJ was involved in the design of hypothesis and concept. All the authors are involved in the drafting and revision of the manuscript. All the authors read and approved the final manuscript.

\section{Acknowledgements}

The authors are grateful to the University Grant Commission (UGC), New Delhi, India for funding the project vide- F. No. 41-543/2012 (SR). Dr. Abhishek Kumar Singh for editing the manuscript and Head, Department of Biotechnology, GGV for his support and encouragement. We also grateful to Dr. Goverdhan Reddy Turpu, Department of Physics, GGV for SEM analysis. SAIF, IIT-Madras, Chennai and SAIF, STIC-Cochin is acknowledged for sample analysis.

\section{Competing interests}

The authors declare that they have no competing interests.

Received: 4 December 2015 Accepted: 11 May 2016

Published online: 27 May 2016

\section{References}

Aadil KR, Barapatre A, Sahu S, Jha H, Tiwary BN (2014) Free radical scavenging activity and reducing power of Acacia nilotica wood lignin. Int J Biol Macromol 67:220-227

Aadil KR, Barapatre A, Meena AS, Jha H (2016) Hydrogen peroxide sensing and cytotoxicity of Acacia lignin stabilized silver nanoparticles. Int J Biol Macromol 82:39-47

Al-Hassan AA, Norziah MH (2012) Starch-gelatin edible films: water vapor permeability and properties as affected by plasticizers. Food Hydrocoll 26:108-117

ASTM (2001) Standard test method for tensile properties of thin plastic sheeting, standard designation: D882, Annual book of ASTM standards. American Society for Testing and Materials, Philadelphia

Ban W, Song J, Lucia LA (2007) Influence of natural biomaterials on the absorbency and transparency of starch-derived films: an optimization study. Ind Eng Chem Res 46(20):6480-6485

Barapatre A, Aadil KR, Tiwary BN, Jha H (2015) In vitro antioxidant and antidiabetic activity of biomodified Acacia wood lignin. Int J Biol Macromol 75:81-89

Bergo P, Sobral PJA (2007) Effects of plasticizer on physical properties of pigskin gelatin films. Food Hydrocoll 21(8):1285-1289

Bhat R, Abdullah N, Din RH, Tay GS (2013) Producing novel sago starch based food packaging films by incorporating lignin isolated from oil palm black liquor waste. J Food Eng 119:707-713

Bigi A, Cojazzi G, Panzavolta S, Roveri N, Rubini K (2002) Stabilization of gelatin films by cross linking with genipin. Biomaterials 23(24):4827-4832

Cao N, Fu Y, He J (2007) Mechanical properties of gelatin films cross-linked, respectively, by ferulic acid and tannin acid. Food Hydrocoll 21:575-584

Carvalho RA, Sobral PJA, Thomazine M, Habitante AMQB, Gimenez B, GomezGullen MC, Montero P (2008) Development of edible films based on differently processed Atlantic habitat (Hippoglossus hippoglossus) skin gelatin. Food Hydrocoll 22:1117-1123

Cuq B, Gontard N, Cuq J, Guilbert S (1997) Selected functional properties of fish myofibrillar protein-based films as affected by hydrophilic plasticizers. J Agric Food Chem 45(3):622-626

Dominguez JC, Oliet M, Alonso MV, Gilarranz MA, Rodriguez F (2008) Thermal stability and pyrolysis kinetic of organosolv lignins obtained from Eucalyptus globulus. Ind Crops Prod 27(2):150-156

Gómez-Guillén MC, Ihl M, Bifani V, Silva A, Montero P (2007) Edible films made from tuna-fish gelatin with antioxidant extracts of two different murta ecotypes leaves (Ugni molinae Turcz.). Food Hydrocoll 21(7):1133-1143

Gordobil O, Egues I, Llano-Ponte R, Labidi J (2014) Physico-chemical properties of PLA lignin blends. Polym Degrad Stab 108:330-338
Hoque MS, Benjakul S, Prodpran T (2011) Effects of partial hydrolysis and plasticizer content on the properties of film from cuttlefish (Sepia pharaonis) skin gelatin. Food Hydrocoll 25(1):82-90

Hosseini SF, Rezaei M, Zandi M, Farahmandghavi F (2015) Fabrication of bio-nanocomposite films based on fish gelatin reinforced with chitosan nanoparticles. Food Hydrocoll 44:172-182

Huang J, Zhang L, Chen F (2003) Effects of lignin as a filler on properties of soy protein plastics. I. Lignosulfonate. J Appl Polym Sci 88(14):3284-3290

Jongjareonrak A, Benjakul S, Visessanguan W, Prodpran T, Tanaka M (2006) Characterization of edible films from skin gelatin of brown stripe red snapper and bigeye snapper. Food Hydrocoll 20(4):492-501

Karnnet S, Potiyaraj P, Pimpan V (2005) Preparation and properties of biodegradable stearic acid-modified gelatin films. Polym Degrad Stab 90(1):106-110

Ma W, Tang C, Yin S, Yang X, Wang Q, Liu F, Wwi Z (2012) Characterization of gelatin-based films incorporated with olive oil. Food Res Int 49:572-579

Milczarek G, Rebis T, Fabianska J (2013) One step synthesis of lignosulphonate-stabilized silver nanopartilcles. Colloids Surf B 105:335-341

Mu C, Gua J, Li X, Lin W, Li D (2012) Preparation and properties of dialdehyde carboxymethyl cellulose cross linked gelatin edible films. Food Hydrocoll 27(1):22-29

Nunez-Flores R, Giménez B, Fernández-Martín F, López-Caballero ME, Montero MP, Gómez-Guillén MC (2012) Role of lignosulphonate in properties of fish gelatin films. Food Hydrocoll 27(1):60-71

Nunez-Flores R, Gimenez B, Fernandez-Martin F, Lopez-Caballero ME, Montero MP, Gomez-Guillen MC (2013) Physical and functional characterization of active fish gelatin films incorporated with lignin. Food Hydrocoll 30(1):163-172

Park Y, Doherty WOS, Halley JP (2008) Developing lignin-base resin coating and composites. Ind Crops Prod 27:163-167

Pena C, Caba K, Eceiza A, Ruseckaite R, Mondragon I (2010) Enhancing water repellence and mechanical properties of gelatin film by tannin addition. Bioresour Technol 101:6836-6842

Rivero S, García MA, Pnotti A (2010) Correlations between structural, barrier, thermal and mechanical properties of plasticized gelatin films. Innov Food Sci Emerg Technol 11:369-375

Sahoo S, Seydibeyogl MO, Mohanty AK, Misra M (2011) Characterization of industrial lignins for their utilizations in future value added applications. Biomass Bioenergy 35(10):4230-4237

Saini JK, Saini R, Tewari L (2015) Lignocellulosic agriculture wastes as biomass feedstocks for second-generation bioethanol production: concepts and recent developments. 3 Biotech 5(4):337-353

Sivasankarapillai G, McDonald AG (2011) Synthesis and properties of ligninhighly branched poly (ester-amine) polymeric systems. Biomass Bioener 35(2):919-931

Skehan P, Storeng R, Scudiero D, Monks A, McMahon J, Vistica T, Warren JT, Bokesh H, Kenney S, Boyd MR (1990) New colorimetric cytotoxicity assay of anticancer drug screening. J Natl Cancer Inst 82(13):1107-1112

Ugartondo V, Mitjans M, Vinardell MP (2008) Comparative antioxidant and cytotoxic effects of lignins from different sources. Bioresour Technol 99(14):6683-6687

Vanin FM, Sobral PJA, Menegalli FM, Carvalho RA, Habitante AMQB (2005) Effect of plasticizers and their concentration on thermal and functional properties of gelatin based films. Food Hydrocoll 19(5):899-907

Wang M, Leitch M, Xu C (2009) Synthesis of phenol-formaldehyde resol resins using oraganosolv pine lignins. Eur Polymer J 45(12):3380-3388

Zeng J, Tong Z, Wang L, Zhu JY, Ingram L (2014) Isolation and structural characterization of sugarcane bagasse lignin after dilute phosphoric acid plus steam explosion pretreatment and its effect on cellulose hydrolysis. Bioresour Technol 154:274-281 